\title{
Prototype Aplikasi Sistem Inventory Barang Berbasis Web
}

\author{
Erna Astriyani ${ }^{1}$, Nanda Try Aditya ${ }^{2}$, Denis Jabbar Nur $^{3}$ \\ Dosen Akuntansi Universitas Raharja ${ }^{1}$, Mahasiswa Universitas Raharja ${ }^{2}$, Mahasiswa \\ Universitas Raharja ${ }^{3}$ \\ Jl. Jend. Sudirman No. 40, Modern Cikokol, Tangerang \\ erna.astriyani@raharia.info ${ }^{1}$, nanda@raharia.info ${ }^{2}$, nanda@raharja.info ${ }^{3}$
}

\begin{abstract}
Abstrak
Permasalahan yang sering terjadi pada sistem yang sedang berjalan yaitu pengolahan data barang masuk, data barang keluar, hingga pembuatan laporan stok hanya dicatat pada selembar kertas kemudian di copy kembali menggunakan komputer dengan Microsoft Excel, kemudian dicetak dan diserahkan ke pimpinan perusahaan, sehingga terkadang mengalami kendala dan kesulitan dalam menghitung barang dan informasi yang diberikan terkadang tidak sesuai dengan ketersediaan barang yang ada, masalah inventory barang tersebut tidak terintegrasi ke dalam suatu sistem sehingga membuat kinerja perusahaan menjadi lambat. Dari permasalahan yang dihadapi peneliti dengan menggunakan metode UML (Unified Modelling Language) mendeskripsikan sistem inventory yang sedang berjalan, kemudian membuat web prototype untuk inventory barang masuk, barang keluar dan laporan persediaan hingga kegiatan pergudangan yang terkomputerisasi dan terintegrasi untuk mempercepat kinerja perusahaan khususnya di bagian pergudangan. Berdasarkan uraian di atas, laporan ini menganalisis inventory barang agar lebih mudah memperoleh dan mengeluarkan informasi yang akan memberikan sistem persediaan barang yang lebih baik.
\end{abstract}

Kata Kunci : prototype, sistem inventory, web

\begin{abstract}
Abstrack
Problems that often occur in an ongoing system, namely processing incoming goods data, outgoing goods data, and making stock reports are only recorded on a sheet of paper and then copied again using a computer with Microsoft Excel, then printed and submitted to the company leadership, so sometimes experiencing problems and difficulties in calculating goods and the information provided is sometimes not in accordance with the availability of existing goods, the problem of inventory of these goods is not integrated into a system so that it makes company performance slow. From the problems faced by researchers using the UML (Unified Modeling Language) method to describe the current inventory system, then create a web prototype for inventory of incoming goods, outgoing goods and inventory reports to computerized and integrated warehousing activities to accelerate company performance, especially in the warehousing section. . Based on the description above, this report analyzes inventory of goods to make it easier to obtain and release information that will provide a better inventory system.
\end{abstract}

Keywords: prototype, inventory system, web 


\section{PENDAHULUAN}

Perkembangan teknologi saat ini begitu pesat dari waktu ke waktu sehingga pekerjaan manusia pada umumnya dapat diselesaikan dengan cepat. Teknologi merupakan sebuah sarana untuk mencapai tujuan instrumental dengan penemuan semua peralatan modern sebagai aktivitas manusiawi yang antropologis (Mulyadi, 2020:7). Seiring kemajuan teknologi, persaingan bisnis di dunia industri semakin ketat. Jumlah perusahaan semakin bertambah dan terus berupaya untuk meningkatkan strategi dan mempertahankan bisnisnya. Dalam mempertahankan usahanya tidak lepas dari peran perusahaan dalam mengolah inventory barang sehingga dapat memenuhi permintaan pelanggan semaksimal mungkin. Perusahaan yang dapat mengontrol pemrosesan persediaan barangnya dengan baik akan dapat memenuhi permintaan pelanggannya sehingga dapat mempertahankan kelangsungan bisnisnya di industri seta 4.0 digital. inventory barang merupakan hal yang penting bagi suatu perusahaan, karena dari inventory tersebut dapat mengolah stok barang gudang yang nantinya akan didistribusikan kepada konsumen.

Perusahaan harus memanfaatkan teknologi informasi sebagai acuan dalam pengolahan data, agar dapat mengikuti arus era globalisasi. Demikian juga perusahaan harus berinovasi dalam membuat media sistem informasi untuk kebutuhan perusahaan itu sendiri dalam pengendalian inventory barang dengan adanya sistem informasi inventory barang yang baik, hal ini dapat sangat mempengaruhi perkembangan serta kemajuan perusahaan atau instansi yang bergerak di bidang produksi. Sistem inventory yang buruk akan menyebabkan kurangnya kepercayaan pada konsumen.

Sistem inventory barang yang saat ini berjalan menggunakan sistem komputerisasi yang masih membutuhkan banyak dokumen dan tidak adanya sistem pergudangan, hal ini memungkinkan terjadinya banyak kesalahan yaitu selisih stok yang ada dan permintaan pelanggan terhadap perusahaan ada kemungkinan akan terjadi kesalahan dan terdapat informasi penyajian stok barang gudang yang tidak tepat untuk pimpinan.

Berdasarkan permasalahan yang ditemukan dari proses-proses yang terjadi di gudang maka perlu dibangun sistem informasi yang dapat mempermudah proses-proses yang ada di gudang dan pihak terkait. Sebagai solusi dari permasalahan diatas, maka penulis tertarik untuk merancang atau membuta suatu sistem informasi inventory barang dengan berbasis web.

Pada penelitian sebelumnya dilakukan oleh (Sutuno, 2019) yang diberi judul "Perancangan Sistem Inventory Berbasis Web Menggunakan Metode Prototype". Penelitian ini menggunakan model prototype dalam bentuk komunikasi, quick plan, modeling, construction dan deployment delivery feedback yang bertujuan untuk memudahkan proses inventory sepatu dengan memberikan informasi data barang dan stok, serta mengurangi terjadinya perbedaan stok dan penanganan proses pelaporan data barang. Penelitian yang dilakukan oleh (Wicaksono dan Samsoni, 2020) dengan judul "Perancangan Aplikasi Sistem Inventory Gudang di PT. Bank Tabungan Negara (Persero) Tbk Cabang Depok". pembuatan sistem aplikasi inventory berbasis java menggunakan model the Unified Modeling Language (UML) dengan aplikasi NetBeans $I D E 8.1$ dan $M y S Q L$ untuk perancangan basis datanya. yang memudahkan kinerja petugas gudang serta dapat mengontrol jumlah persediaan yang tersedia dengan banyaknya permintaan kebutuhan karyawan/i PT Bank Tabungan Negara Kantor Cabang Depok. Penelitian yang dilakukan oleh (Susanti dan Sihombing, 2020) dengan judul "Rancangan Sistem Aplikasi Inventory Pada Pondok Pesantren SMP Ashhaburratib Almadani Berbasis Java". Dalam penelitian ini menggunakan metode waterfall dan pembautan sistem menggunakan java desktop dan database MySQL untuk mengetahui proses pemesanan dan pembelian inventory pada SMP Ashhaburratib Almadani. Penelitian yang dilakukan oleh (Ilamsyah dkk, 2020) yang diberi judul "Prototype Aplikasi Analisa Sistem Informasi Inventory Barang Pada PT Anugrah Distributor Indonesia". Dalam penelitian ini menghasilkan sistem informasi persediaan yang 
sesuai dengan kebutuhan dan memudahkan pengguna dalam menginput dan membuat laporan persediaan, agar proses persediaan dapat terkontrol dengan baik, efektif dan efisien.

Dari keempat penelitian di atas yang telah diuraikan maka dapat disimpulkan bahwa inventory barang sangat membutuhkan sistem berbasis web yang dapat memberikan informasi yang cepat dan akurat tentang persediaan yang terjadi di masing-masing perusahaan.

\section{TINJAUAN PUSTAKA}

Untuk memahami tentang permasalahan sistem penulis memberikan beberapa ahli yaitu: pendapat (Anwar, 2020:4) Sistem merupakan kumpulan dari bagian-bagian yang saling berhubungan dan bergantung serta diatur sedemikian rupa sehingga menghasilkan secara utuh.

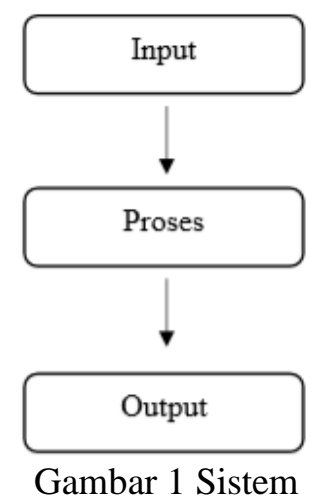

Perancangan prototype menggunakan software Adobe $x d$ (experience design), menurut pendapat (Huddleston, 2017) Dalam membangun sebuah aplikasi baik itu aplikasi dalam bentuk website, mobile maupun desktop tentunya ada tahapan-tahapan yang dimulai dengan menganalisa masalah hingga rilis, dari hulu ke hilir. Pengkodean hanyalah sebagian kecil dari membangun aplikasi. Biasanya sebelum tahap development / coding kita harus melalui tahap design terlebih dahulu agar development bisa terarah dan terstruktur serta meminimalkan seringnya revisi. Tahap desain umumnya terdiri dari pembuatan mockup atau prototype.

Pendapat (Candra, 2019:2) informasi didefinisikan sebagai data yang berguna (relevan) bagi pengguna atau data yang telah diolah menjadi bentuk yang berguna bagi user. Perlu diperhatikan bahwa yang bisa disebut sebagai informasi adalah data yang telah diolah menjadi bentuk yang bermanfaat, bukan sekedar bermakna.

Pendapat (Vikaliana dkk, 2020: 3) Persediaan adalah kekayaan yang meliputi barang-barang milik perusahaan dengan maksud untuk dijual dalam jangka waktu usaha yang normal, atau persediaan barang yang masih dalam proses produksi atau persediaan barang mentah menunggu untuk digunakan dalam suatu proses produksi.

\section{METODE PENELITIAN}

Ada 3 metode yang digunakan dalam pengumpulan data untuk penelitian ini sebagai berikut ;
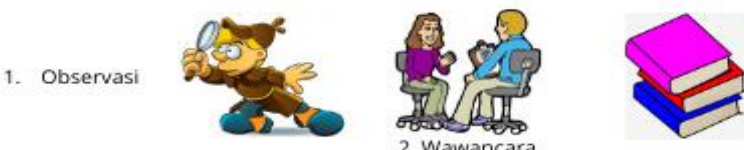

3. Studi Pustaka

Gambar 2 Metode Penelitian 
1. Metode Observasi

Dengan cara mengamati atau memperhatikan langsung tingkah laku dan kegiatan yang dilakukan oleh petugas yang bersangkutan untuk mengumpulkan data sebagai sumber informasi dalam hal ini membantu proses sistem pergudangan.

2. Metode Wawancara

Bertatap muka dan berbicara langsung dari hati ke hati dengan petugas terkait untuk mendapatkan hasil yang murni

3. Studi Pustaka

Kumpulan referensi yang diperoleh untuk kelengkapan data yang berhubungan dengan judul yang diteliti yang dapat diperoleh dari berbagai sumber referensi

\section{HASIL DAN PEMBAHASAN}

Tahapan sistem yang sedang berjalan dijelaskan dalam bentuk diagram use case sebagai berikut

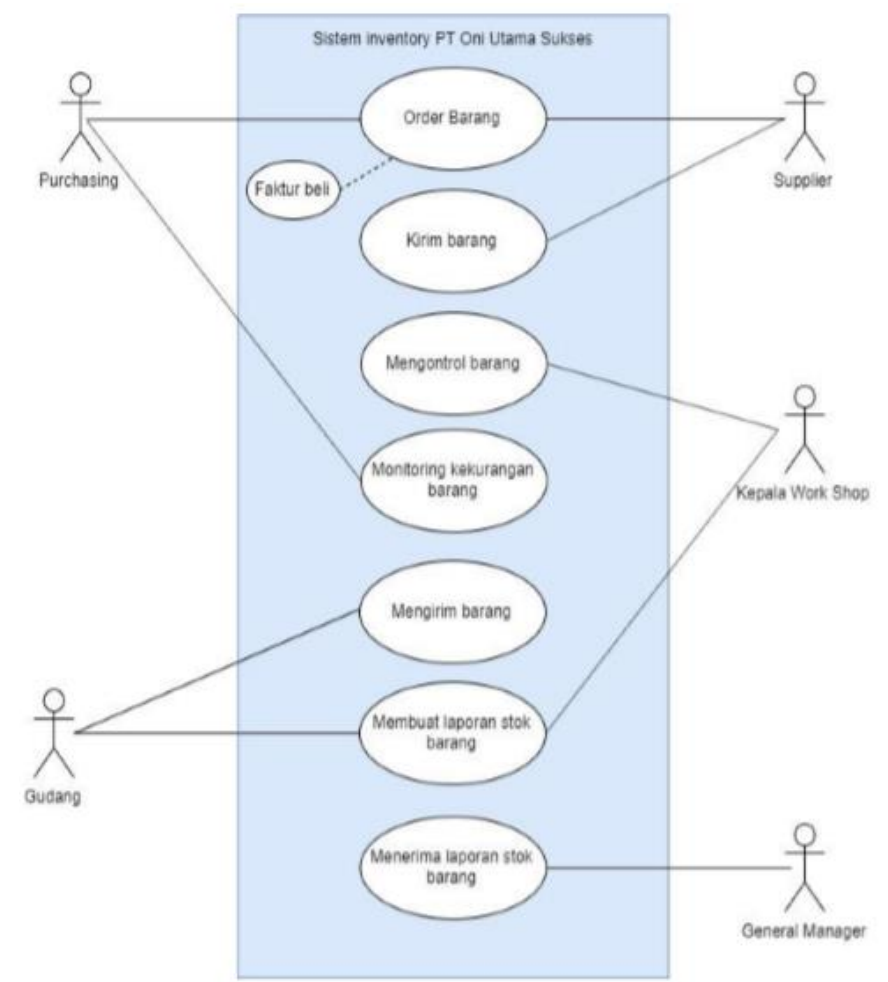

Gambar 3 Use Case Diagram

Berdasarkan dari gambar 3, dapat terlihat bahwa sistem informasi inventory barang memiliki 3 aktor yaitu Supplier, Purchasing, Gudang, Kepala Work Shop dan General Manager, memiliki 7 use case yaitu order barang, kirim barang, mengontrol barang, monitoring kekurangan barang, membuat laporan stok barang, menerima laporan stok barang dengan include faktur beli.

Rancangan program atau tampilan dari Aplikasi Sistem Inventory Barang yang dibuat

a) Tampilan Login

Halaman login ini digunakan untuk masuk kedalam website sistem inventory 


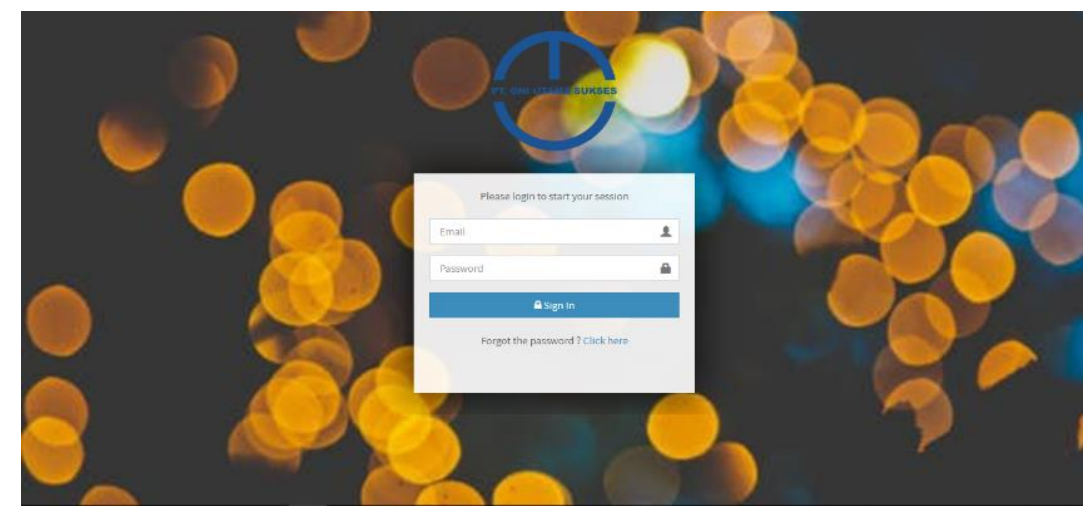

\section{Gambar 4 Tampilan Login}

b) Tampilan Transaksi Barang Masuk

Halaman Transaksi Barang Masuk digunakan untuk mengurus segala transaksi barang yang masuk meliputi : sub menu barang masuk, barang keluar lalu ada tampilan no, kode transaksi, tanggal, kode barang, nama barang, jumlah barang.

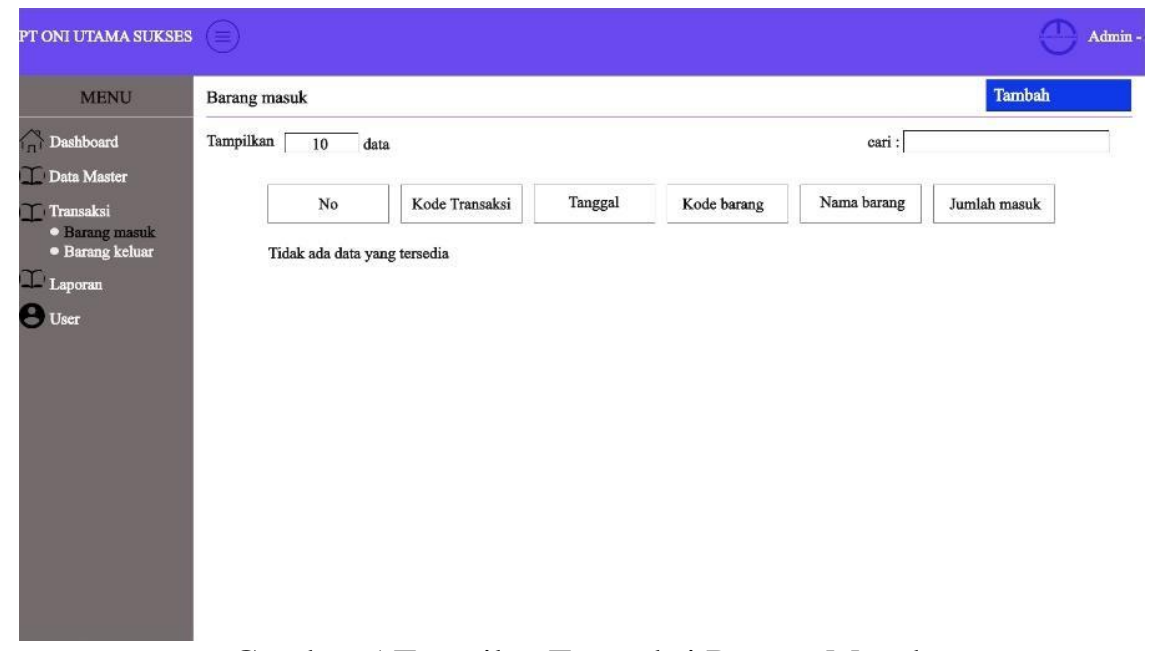

Gambar 5 Tampilan Transaksi Barang Masuk

c) Tampilan Transaksi Barang Keluar

Halaman ini digunakan untuk mengurus segala transaksi barang keluar

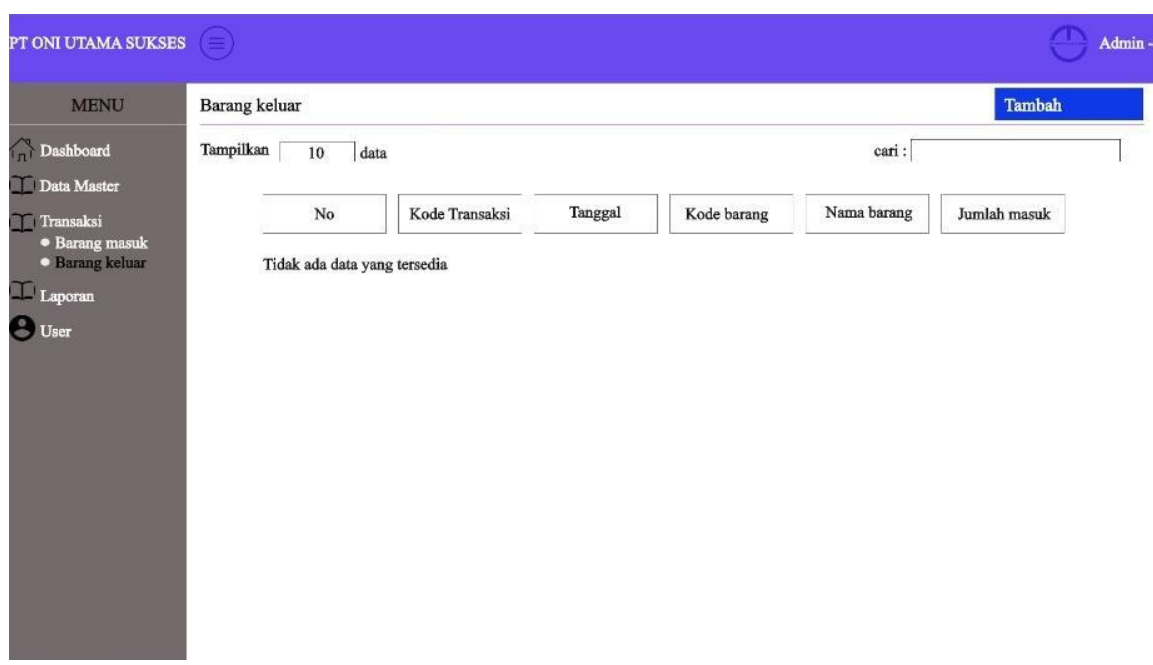




\section{Gambar 6 Tampilan Transaksi Barang Keluar}

d) Tampilan Prototype Halaman Laporan Stok Barang

Halaman ini digunakan untuk membuat laporan atas stok yang tersedia pada gudang

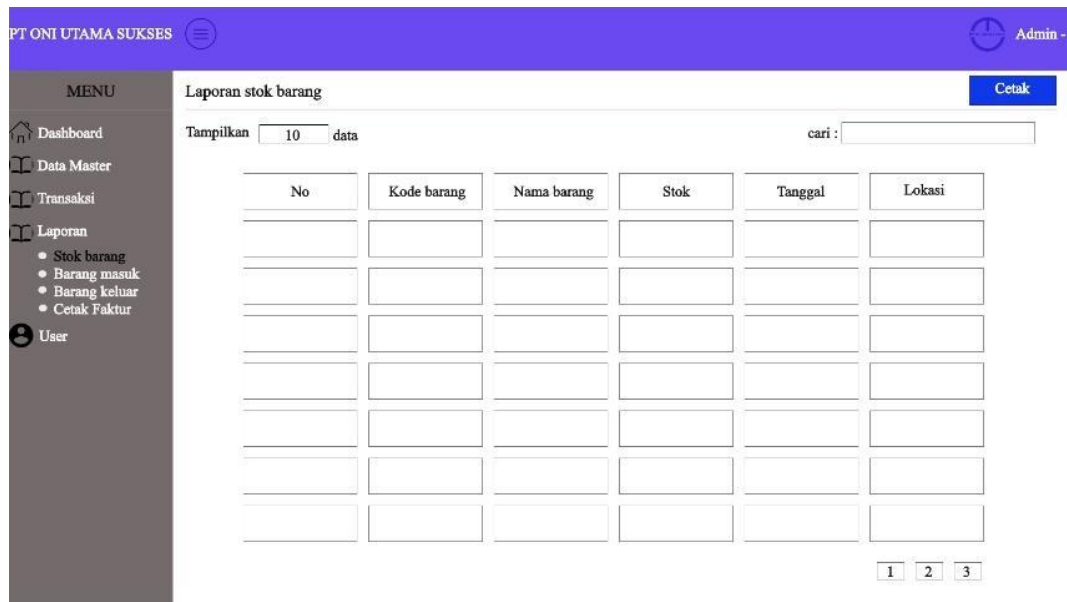

Gambar 7 Prototype Halaman Laporan Stok Barang

e) Tampilan Prototype Halaman Cetak Faktur

Halaman Cetak Faktur digunakan untuk membuat laporan cetak faktur meliputi : sub menu stok barang, barang masuk, barang keluar. Tampilan laporan cetak faktur no, kode transaksi, tanggal, penerima, alamat, total

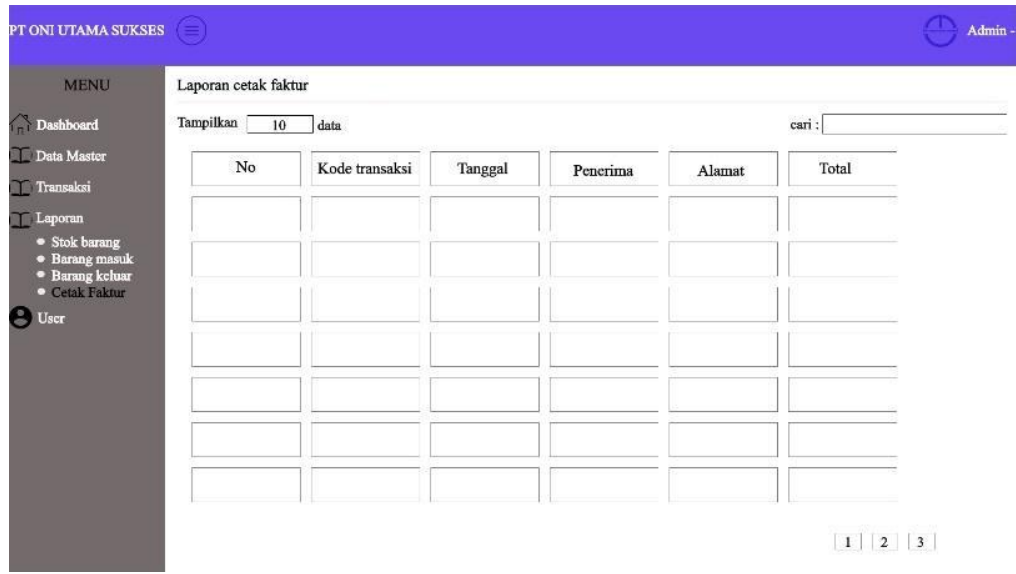

Gambar 8 Prototype Halaman Cetak Faktur

\section{KESIMPULAN}

Berdasarkan hasil penelitian dan observasi yang telah dilakukan pada bagian pergudangan mengenai sistem inventory barang dan sistem inventory yang diusulkan, dapat disimpulkan bahwa:

Sistem inventory barang yang saat ini beroperasi masih terkomputerisasi dan belum terintegrasi dengan sistem yang kokoh serta tentunya belum ada pencatatan khusus kegiatan pergudangan. Dalam menjalankan proses dari barang masuk hingga keluar kemudian proses pencatatan pelaporan masih berbelit-belit dan kurang terstruktur dengan baik, peneliti membuat sebuah prototype desain sistem inventory yang nantinya akan digunakan untuk membuat sistem inventory barang menjadi jauh lebih baik. 


\section{DAFTAR PUSTAKA}

[1] Mulyadi. 2020. Antara Teknologi dan Teologi dalam Pendisiplinan Aktor di Perpustakaan. Depok : PT RajaGrafindo Persada

[2] Sutuno, Eko. 2019. Perancnagan Sistem Inventory Berbasis Web Menggunakan Metode Prototype. Prosiding Seminar Nasional Informatika dan Sistem Informasi, 3(3), 12801285

[3] Wicaksono, Satria Agung., \& Samsoni, Samsoni. 2020. Perancangan Aplikasi Sistem Inventory Gudang di PT Bank Tabungan Negara (Persero) Tbk Cabang Depok. Prosiding Seminar Nasional Informatika dan Sistem Informasi, 5(3), 215-222

[4] Susanti, Mei Lilis., \& Sihombing, Redo Abeputra. 2020. Rancangan Sistem Aplikasi Inventory Pada Pondok Pesantren SMP Ashhaburratib Almadani Berbasis Java. JRAMI, $1(2), 230-237$

[5] Ilamsyah, I., Rahayu, S., \& Lisnawati, D. (2020). Prototype Aplikasi Analisa Sistem Informasi Inventory Barang Pada PT Anugrah Distributor Indonesia. ICIT Journal, 6(1), $50-60$.

[6] Anwar, Muhammad. 2020. Pengantar Dasar Ilmu Manajemen. Jakarta : Kencana

[7] Huddleston, Rob. 2017. Beginning Adobe Experience Design: Quickly Design and Prototype Websites and Mobile Apps. California: Apress

[8] Candra, Heru Kartika. 2019. Pengantar Teknologi Informasi. Banjarmasin : Poliban Press

[9] Vikaliana, Resista dkk. 2020. Manajemen Persediaan. Bandung : Media Sains Indonesia 